\title{
DISA: Encasingbezüge sind effektiv
}

\section{Im Rahmen der momentanen Diskussion über die Wirksamkeit von Milbensanierungsmaßnahmen in Wohnräumen von Allergikern hat die Dokumentations- und Informationsstelle für Allergiefragen im Kindes- und Jugendalter (DISA) jetzt eine umfangreiche Stellungnahme vorgelegt. Unter der Rubrik „Bett“ wird sich unter anderem für den Einsatz von Encasingbezügen ausgesprochen.}

guten Nährboden für Schimmelpilze d a r. Latexmatratzen oder Wa s s e r b e t t e $n$ sind dem Encasing ebenfalls deutlich unterlegen. Eindeutige Hinweise, daß Latexmatratzen zu Sensibilisierungen gegen Latex führen, gibt es bisher nicht.

\section{Kopfkissen: Synthetik nicht schlechter als Federn}

Eine neuere Studie ergab, daß in Synthetikkopfkissen und -oberbetten höhere Milben- und Allerg enkonzentrationen zu finden sind als in Bettzeug mit Federfüllung. Daraus den Schluß zu ziehen, Federbetten seien geeigneter als Synthetikkissen, ist allerdings falsch. Entscheidend ist, daß Synthetikmaterialien bei $60^{\circ} \mathrm{C}$ gewaschen und $\mathrm{da} \beta$ damit die Milben und ihre Exkremente entfernt werden können. Das Waschen muß allerdings auch tatsächlich und häufig genug durchgeführt werden. Nur bei gleichzeitiger Sanierung auch von Matratze, Kopfkissen und Oberbett ist eine optimale Reduktion der Hausstaubmilbenallergenmenge im Bett zu erreichen.

Alternativ bieten sich Encasingbezüge auch für Kopfkissen und Oberbett an, allerdings sind hierbei die Kosten zu bedenken. Ein Vorteil der Encasings ist, daß die Mitnahme in

Encasingbezüge sind erstattungsfähig. Sie sollten alle 3 Monate gewaschen werden. Auch zur Mitnahme auf Urlaubsreisen sind sie aufgrund ihrer Leichtigkeit zu empfehlen. Allergenrückhaltevermöge und im Liegekomfort.

Schadstoffe werden von hochwertigen Encasings nicht freigesetzt. Die Krankenkassen übernehmen bei nachgewiesener relevanter Hausst a u b milb e nalle rgie die Kosten für das Encasing der Matratzen.

\section{Encasings alle 3 Monate waschen}

Neue Matratzen sind, zumindest wenn sie in Plastikfolie eingeschweißt sind, meist milbenfrei. Allerdings werden sie schnell besiedelt, da schnell Allergene und Milben eingeschleppt werden. Dies geht um so rascher, je belasteter die Umgebung ist. Die Kontamination mit Allergenen erfolgt auch auf dem Encasing; daher die Empfehlung des Waschens alle 3 Monate bei $40^{\circ} \mathrm{C}$.

Um mit dem Waschen von Kleidung, Bettzeug und anderen Te x t i l i e n auch bei niedrigeren Temperaturen $\left(<60^{\circ} \mathrm{C}\right)$ die Milben ausreichend abzutöten, kann der Zusatz von akariziden Substanzen wie z.B. Benzylbenzoat oder ätherische Öle den Wascheffekt noch erhöhen. Für das Bett sind allerdings Textilien zu bevorzugen, die bei Temperaturen von über $60^{\circ} \mathrm{C}$ gewaschen werden können. Hier bieten sich Bettbezüge aus Baumwolle an. Häufiges Wechseln des Bettbezugs und des Lakens ist eine zusätzliche hilfreiche Maßnahme.

\section{Matratzen ohne Roßhaarfüllung}

Wird die Matratze umhüllt, so ist der Aufbau der Matratze weniger bedeutsam. Beim Kauf sollte allerdings darauf geachtet werden, daß in ihr kein Roßhaar enthalten ist. Schaumstoffmatratzen führen die Feuchtigkeit schlecht $a b$ und stellen somit einen den Urlaub wesentlich einfacher ist als die des gesamten Bettzeugs.

\section{Keine gepolsterten Bettgestelle}

Das Bettgestell sollte in jedem Fall die Luftzirkulation unter der Matratze erlauben, um auch hier eine gute Abfuhr der Feuchtigkeit zu ermöglichen. Dies verringert zusätzlich das Risiko der Schimmelpilzbesiedlung des Bettes. Ein gepolstertes Bettgestell reduziert den Effekt des Matratzenencasings vollständig.

Quelle: Stellungnahme der Dokumentations- und Informati onsstelle für Allergiefragen im Kindes- und Jugendalte (DISA): „Sinnvolle Wohnraumsanierungsempfehlungen be S. Schmidt, Schriftleitung der DISA in Zusammenarbeit und Abstimmung mit Experten aus dem wissenschaftlichen Forum der DISA: C. P. Bauer, Gaißach; K.-Ch. Bergmann, Bad Lippspringe; J. Forster, Freiburg; Th. Lob-Corzilius, Osnabrück; K. E. von Mühlendahl, Osnabrück; B. Niggemann, Berlin W. Rebien, Hamburg; J. Ring, München; E. Rietschel, Köln G. Schultze-Werninghaus, Bochum; J. Seidenberg, Oldenburg R. Szczepanski, Osnabrück. 